\title{
\begin{tabular}{l|l} 
Mitraries & DSpace@MIT
\end{tabular}
}

\author{
MIT Open Access Articles
}

\section{Microstructured Ceramic-Coated Carbon Nanotube Surfaces for High Heat Flux Pool Boiling}

The MIT Faculty has made this article openly available. Please share how this access benefits you. Your story matters.

Citation: Zhao, Hangbo et al. "Microstructured Ceramic-Coated Carbon Nanotube Surfaces for High Heat Flux Pool Boiling." ACS Applied Nano Materials 2, 9 (September 2019): 5538-5545 (c) 2019 American Chemical Society

As Published: http://dx.doi.org/10.1021/acsanm.9b01116

Publisher: American Chemical Society (ACS)

Persistent URL: https://hdl.handle.net/1721.1/124992

Version: Final published version: final published article, as it appeared in a journal, conference proceedings, or other formally published context

Terms of use: Creative Commons Attribution-NonCommercial-NoDerivs License 


\title{
Microstructured Ceramic-Coated Carbon Nanotube Surfaces for High Heat Flux Pool Boiling
}

\author{
Hangbo Zhao, ${ }^{\dagger}$ Susmita Dash, ${ }^{\dagger}$, Navdeep Singh Dhillon, $^{\dagger}$ Sanha Kim, ${ }^{\dagger}$ Bethany Lettiere, ${ }^{\dagger}$ \\ Kripa K. Varanasi, ${ }^{\dagger}$ and A. John Hart* ${ }^{*} \dagger$
}

${ }^{\dagger}$ Department of Mechanical Engineering and Laboratory for Manufacturing and Productivity, Massachusetts Institute of Technology, 77 Massachusetts Avenue, Cambridge, Massachusetts 02139, United States

${ }^{\ddagger}$ Department of Mechanical Engineering, Indian Institute of Science, Bangalore 560012, India

\section{Supporting Information}

ABSTRACT: Stable surfaces with high boiling heat flux are critical to many thermal and energy conversion systems, and it is well-known that the microscale texture and wettability of a surface influences its critical heat flux (CHF). We investigate pool boiling on microstructured ceramic-coated carbon nanotube (CNT) surfaces. CNT microstructures are patterned with precise dimensions over large areas, and a ceramic coating by atomic layer deposition (ALD) imparts stability in the presence of capillary forces and thermal stresses that occur during boiling, achieving a measured CHF as high as $245 \mathrm{~W} \mathrm{~cm}^{-2}$. We also show that the nanoporosity of the ceramic-CNT microstructures has a negligible influence on
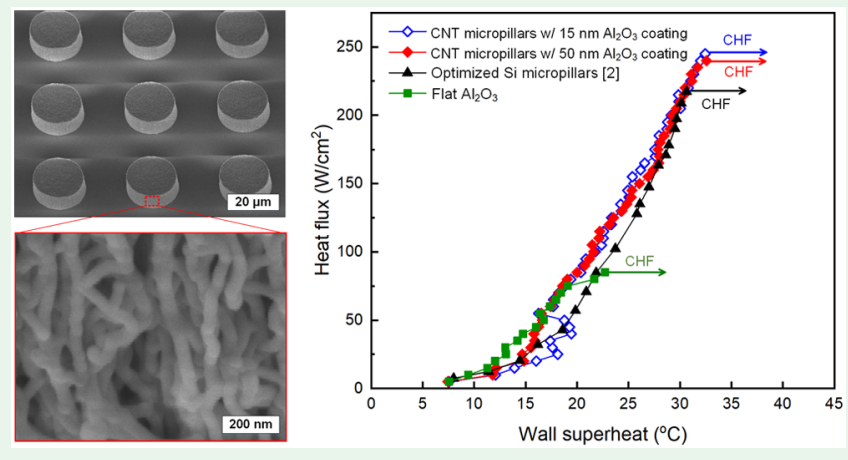
the CHF because surface rewetting is dominated by microscale imbibition. The high CHF values achieved on our surfaces are attributed to the micropatterning and the nanoscale surface texture of the CNTs, which accelerate liquid imbibition upon bubble departure. Our findings also suggest further enhancements in CHF can be made by optimizing the microstructure pattern and improving its wettability. Therefore, micropatterned ceramic-CNT composites are a potentially attractive substrate for industrial applications of pool boiling.

KEYWORDS: carbon nanotubes, microstructures, nanoporous, boiling, surfaces, scalable fabrication

\section{INTRODUCTION}

Boiling is a highly efficient means of transferring heat due to the large latent heat of vaporization. However, there exists a practical limitation in the maximum heat flux a boiling surface can safely transfer, and this is called the critical heat flux (CHF). Beyond the CHF, a vapor layer forms between the liquid and the heating surface, and a transition from nucleate boiling to film boiling occurs. This leads to a drastic increase in the substrate temperature and often causes burnout of the boiling surface, a phenomenon often termed the boiling crisis. $\mathrm{CHF}$ therefore sets an upper limit for the safe operations of boiling equipment such as water-cooled nuclear reactors, industrial boilers, and cooling systems for high-power electronics.

Increasing the $\mathrm{CHF}$, thereby mitigating the boiling crisis, is desirable for energy savings and operational safety of boiling systems. Extensive research has focused on the mechanistic understanding of the CHF; in particular, experiments have suggested that a high $\mathrm{CHF}$ is strongly correlated to fast liquid rewetting of hot dry spots on the boiling surface upon bubble departure. ${ }^{1,2}$ Various micro- and nanostructured hydrophilic surfaces have been created. Examples include surfaces with microparticles, ${ }^{3}$ nanowires, ${ }^{4,5}$ and silicon micropillars ${ }^{6}$ fab- ricated by deposition/etching and metallic textures fabricated by scalable laser ablation, ${ }^{7,8}$ yet there are limitations to the fabrication scalability, to structural hierarchy and tunability, and to the CHF that can be obtained on those surfaces.

Engineered carbon nanotubes (CNTs) can provide a scalable platform to engineer key characteristics of boiling surfaces and to study the roles of microscale and nanoscale imbibition. CNTs have been used in various thermal engineering applications because of their high intrinsic thermal conductivity ( $>3000 \mathrm{~W} \mathrm{~m}^{-1} \mathrm{~K}^{-1}$ ), ${ }^{9}$ mechanical strength, and thermal stability. Such applications include thermal interfacial materials (TIMs), ${ }^{10,11}$ heaters, ${ }^{12}$ thermal energy storage materials, ${ }^{13}$ additives in nanofluids, ${ }^{14,15}$ and phase change heat transfer devices. ${ }^{16,17} \mathrm{CNTs}$ are particularly attractive for engineering of phase change heat transfer due to their high surface-to-volume ratio and nanoscale geometry, which give large surface areas compared to planar or solid microstructured surfaces and provide high capillary pressures. In boiling applications, thin coatings of randomly oriented CNTs have

Received: June 11, 2019

Accepted: August 19, 2019

Published: August 19, 2019 
a

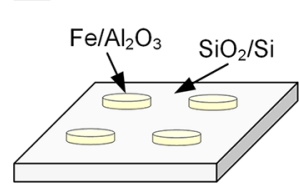

Catalyst deposition

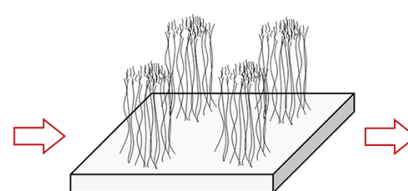

CNT growth

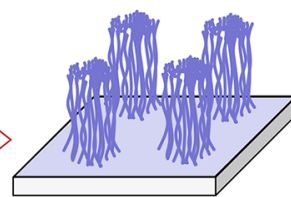

$\mathrm{Al}_{2} \mathrm{O}_{3}$ coating
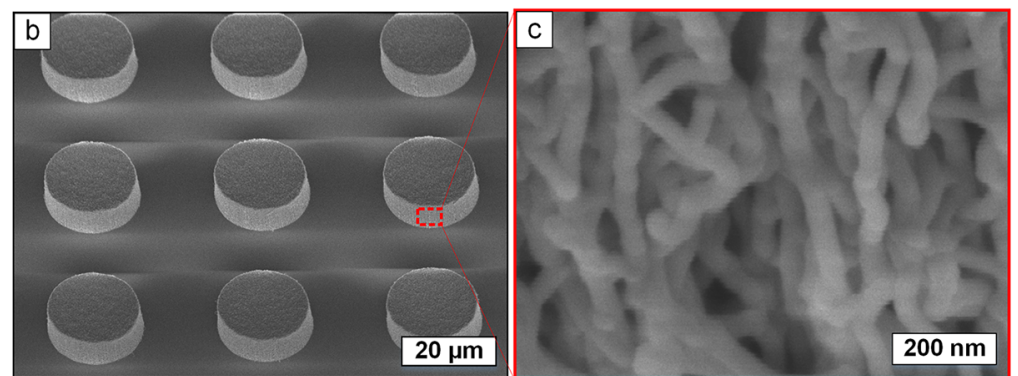

d

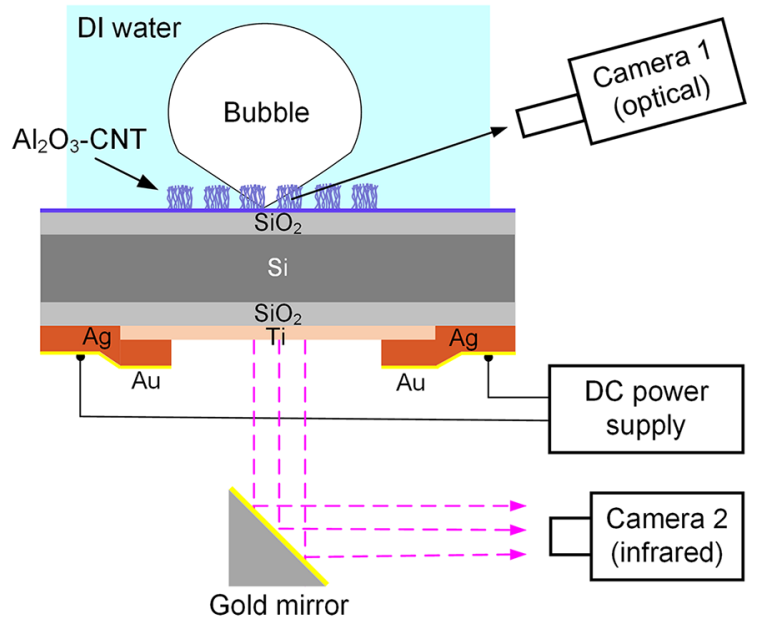

Figure 1. Pool boiling using microstructured $\mathrm{Al}_{2} \mathrm{O}_{3}$-coated CNT surfaces. (a) Schematic of the fabrication process. (b) SEM image of a portion of an $\mathrm{Al}_{2} \mathrm{O}_{3}$-coated CNT micropillar array. (c) Close-up SEM image of the CNTs conformally coated with $\mathrm{Al}_{2} \mathrm{O}_{3}$ via $\mathrm{ALD}$ ( $150 \mathrm{ALD}$ cycles, $\sim 15 \mathrm{~nm}$ coating thickness). (d) Schematic of the experimental setup for pool boiling experiments.

been used on other structures to enhance surface wettability. ${ }^{18,19}$ CNT forests-aligned films of CNTs oriented perpendicular to the substrate-have been utilized in stable boiling only with refrigerants as the working liquids. ${ }^{20,21}$ In high-surface-tension liquids such as water, densification of CNT forests occurs due to elastocapillary effects. ${ }^{2,23}$

Here we propose and demonstrate the use of ceramic-coated $\mathrm{CNT}$ forest microstructures as a scalable, stable, high $\mathrm{CHF}$ boiling surface. The conformal ceramic coating on the CNTs prevents CNT densification or detachment from the substrate. The CNT forests effectively reduce the local liquid contact angle to zero through their nanoscale texture while maintaining liquid permeability through microscale patterning, resulting in a high $\mathrm{CHF}$.

\section{METHODS}

Fabrication of CNT Microstructures. A (100) silicon wafer with $3000 \AA$ of thermally grown oxide layers on both sides is used as the substrate for CNT growth. A supported catalyst layer of $\mathrm{Fe} / \mathrm{Al}_{2} \mathrm{O}_{3}$ (1 $\mathrm{nm} / 10 \mathrm{~nm}$, deposited by electron beam evaporation) is patterned by photolithography and lift-off. The wafer is then cut into $30 \times 20 \mathrm{~mm}^{2}$ pieces with the catalyst area centered and placed in a chemical vapor deposition (CVD) furnace for CNT growth. The growth recipe starts by flowing $100 / 400 \mathrm{sccm}$ (standard cubic centimeters per minute) of $\mathrm{He} / \mathrm{H}_{2}$ while heating the furnace to $775{ }^{\circ} \mathrm{C}$ over $10 \mathrm{~min}$ and then maintaining the furnace at $775{ }^{\circ} \mathrm{C}$ for $10 \mathrm{~min}$ with the same gas flow. Then, the gas flow is changed to $100 / 400 / 100 \mathrm{sccm}$ of $\mathrm{C}_{2} \mathrm{H}_{4} / \mathrm{He} / \mathrm{H}_{2}$ at $775{ }^{\circ} \mathrm{C}$ for CNT growth. The vertical growth rate of the CNTs is $\sim 60 \mu \mathrm{m} / \mathrm{min}$, and the growth duration is chosen according to the desired height. The CVD furnace is opened immediately after the end of the CNT growth step, causing the tube and sample to cool rapidly while maintaining the same gas flow. This results in improved CNTsubstrate adhesion. ${ }^{24}$ When the temperature is below $100{ }^{\circ} \mathrm{C}$, the furnace is purged with $1000 \mathrm{sccm}$ of $\mathrm{He}$ for $5 \mathrm{~min}$.

Atomic Layer Deposition (ALD) of $\mathrm{Al}_{2} \mathrm{O}_{3} \cdot \mathrm{Al}_{2} \mathrm{O}_{3}$ is deposited onto the CNTs by atomic layer deposition (ALD; Gemstar, Arradiance Corporation). ${ }^{22}$ Trimethylaluminum (TMA) and ozone $\left(\mathrm{O}_{3}\right)$ are used as the metallorganic and oxidizing precursors, respectively. By use of nitrogen as the carrier gas at a flow rate of $40 \mathrm{sccm}$, TMA and $\mathrm{O}_{3}$ are sequentially pulsed into the deposition chamber $\left(2-3\right.$ Torr, $\left.175{ }^{\circ} \mathrm{C}\right)$ for 22 and $100 \mathrm{~ms}$, respectively. Following each precursor pulse, the chamber is purged with $90 \mathrm{sccm}$ of nitrogen for $28 \mathrm{~s}$.
Deposition of Heater and Electrical Contacts. A thin-film heater $\left(1 \times 2 \mathrm{~cm}^{2}\right.$, Figure S1) is patterned on the backside of the $\mathrm{Al}_{2} \mathrm{O}_{3}$-coated CNT sample by sputtering of $\mathrm{Ti}(150 \mathrm{~nm})$ through a shadow mask. A stack of $\mathrm{Ti} / \mathrm{Ag} / \mathrm{Au}(10 \mathrm{~nm} / 300 \mathrm{~nm} / 50 \mathrm{~nm})$ is then sputtered as electrical contacts by using the same shadow patterning method. The patterned electrical contacts precisely define an effective heater area of $1 \times 1 \mathrm{~cm}^{2}$, which is the Ti area between the electrical contact pads. After the deposition of the Ti heater and the electrical contacts, the sample is placed onto a machined stainless steel holder. Thermal epoxy (DP190 Gray, 3M Scotch-Weld) is applied around the sample to adhere the sample to the holder and seal the gaps in between. The epoxy is then cured at $60{ }^{\circ} \mathrm{C}$ for $36 \mathrm{~h}$.

Pool Boiling Experiments and CHF Measurements. Deionized (DI) water used for boiling experiments is degassed by boiling for $20 \mathrm{~min}$ in a microwave. The degassed DI water is then poured into a stainless steel boiling chamber ${ }^{2}$ containing the $\mathrm{Al}_{2} \mathrm{O}_{3}-\mathrm{CNT}$ sample. Before the measurement is taken, boiling is initiated and maintained for $20 \mathrm{~min}$ to completely degas the system, including removing any air trapped within the $\mathrm{Al}_{2} \mathrm{O}_{3}-\mathrm{CNT}$ structures. To keep the DI water at saturation, the inner walls of the boiling chamber are maintained at $100{ }^{\circ} \mathrm{C}$ by flowing a hot $1: 1$ solution of water and propylene glycol in a metal jacket surrounding the chamber. The boiling experiments are run at atmospheric pressure. A high-speed optical camera (FASTCAM SA1.1, Photron) is focused on the CNT surface at an inclined angle, and a high-speed infrared camera (IRC900, IRCameras) is focused on the $\mathrm{Ti}$ heater on the backside of the boiling sample using a gold mirror. During the boiling test, the power to the heater is applied by a dc power supply and controlled by a LabVIEW program. The power is increased in steps of $5 \mathrm{~W} \mathrm{~cm} \mathrm{~cm}^{-2}$ until $\mathrm{CHF}$ is reached, when the $\mathrm{Ti}$ heater undergoes a rapid rise in temperature and the sample breaks because of the thermal shock. At each intermediate step the optical and infrared videos are concurrently recorded for $400 \mathrm{~ms}$ at frame rates of 2000 and 1250 fps, respectively.

\section{RESULTS AND DISCUSSION}

Microstructured CNT surfaces are fabricated by lithographic patterning of a supported catalyst thin film on silicon wafers, followed by a scalable chemical vapor deposition (CVD) process for CNT growth (Figure 1a, see the Methods section). The microstructure pattern is defined by photolithography, and the CNT height is controlled by the growth duration. Then, the CNTs are coated with a conformal layer of $\mathrm{Al}_{2} \mathrm{O}_{3}$ via a scalable atomic layer deposition (ALD) (Figure $1 \mathrm{~b}, \mathrm{c}$ ), at a 
rate of $\sim 0.1 \mathrm{~nm}$ per deposition cycle. ALD uses trimethylaluminum (TMA) and ozone $\left(\mathrm{O}_{3}\right)$ as the metallorganic and oxygen precursors, respectively. Ozone also etches the surface of CNTs, increasing the density of surface defects which serve as nucleation sites for the uniform coating. ${ }^{22,26}$ The contact angle of water on $\mathrm{ALD} \mathrm{Al}_{2} \mathrm{O}_{3}$ (deposited on a flat reference substrate) is $\theta \approx 60^{\circ}$ prior to boiling tests; even though the pristine $\mathrm{Al}_{2} \mathrm{O}_{3}$ surface is superhydrophilic, ${ }^{27}$ the hydrophilicity deteriorates after exposing the sample to ambient air due to hydrocarbon adsorption. ${ }^{28}$

To facilitate boiling experiments on the ceramic-coated CNT surfaces, a Ti resistive heater and electrical contacts are patterned and deposited on the backside of the sample through shadow masks (see the Methods section and Figure S1). Pool boiling experiments are performed in a custom-built boiling rig, operated at atmospheric pressure. A schematic and photograph of the experimental setup are shown in Figure 1d and Figure S2, respectively. Boiling dynamics are captured by a high-speed optical camera (angled top view), and the temperature of the infrared-opaque Ti heater at the backside of the substrate is measured with a high-speed infrared camera (bottom view). The temperature of the boiling surface is then calculated by using Fourier's law. Details of the calculation and measurement uncertainties can be found in the Supporting Information. When the CHF is reached, the silicon substrate fractures due to the large thermal shock to the sample adhered to the holder (Figure S3).

The liquid imbibition dynamics on microtextured surfaces depend on the geometry of the microstructure, surface wettability, and liquid properties. ${ }^{29,30}$ The influence of microstructure pattern on liquid rewetting and CHF has been studied experimentally and analytically. ${ }^{1}$ For arrays of solid micropillars, the liquid imbibition rate is maximized at intermediate pillar density because of the balance between capillary driving force and viscous drag. In this study, a CNT micropillar array with center-to-center distance $(p)$ of $25 \mu \mathrm{m}$ and pillar diameter $(d)$ of $20 \mu \mathrm{m}$ is chosen (see later section and the Supporting Information). For the CNT micropillar height $h$, the imbibition rate increases with micropillar height for short pillars $(h<p) .{ }^{30}$ However, for boiling surface design, the temperature drop across the microstructures must also be considered. Importantly, the bulk thermal conductivity of CNT forest decreases with height because of decreasing CNT forest density in the height direction. ${ }^{31}$ To balance these requirements, we chose the $\mathrm{CNT}$ height to be $\sim 10 \mu \mathrm{m}$. Initial experimentation with taller (130 and $50 \mu \mathrm{m}$ ) CNT microstructures (after ceramic coating) showed no boiling above the $\mathrm{CNT}$ area $\left(\right.$ at $\left.q^{\prime \prime}=25 \mathrm{~W} \mathrm{~cm}^{-2}\right)$ and a low CHF $\left(60 \mathrm{~W} \mathrm{~cm}^{-2}\right)$, respectively, validating this hypothesis.

Moreover, considering the significant forces exerted during wetting, bubble nucleation, and departure, we found it necessary to engineer the CNTs to prevent structural deformation or detachment from substrates. This was accomplished by modifying the CNT growth recipe to provide strong adhesion to the substrate (see the Methods section) and by coating the CNTs with $\mathrm{Al}_{2} \mathrm{O}_{3}$ above a certain thickness. ${ }^{18}$ Here, two CNT micropillar arrays with the same microstructure geometry are coated with $\sim 2 \mathrm{~nm}$ (20 ALD cycles) and $\sim 15 \mathrm{~nm}$ (150 ALD cycles) $\mathrm{Al}_{2} \mathrm{O}_{3}$ coating (Figure $\mathrm{S} 4$ ). The sample with $\sim 2 \mathrm{~nm} \mathrm{Al}_{2} \mathrm{O}_{3}$ coating reached a CHF of $150 \mathrm{~W}$ $\mathrm{cm}^{-2}$. SEM images after CHF show that most of the $\mathrm{Al}_{2} \mathrm{O}_{3}$ coated CNTs detached from the substrate, and the remaining CNT pillars densified (Figure 2a). The sample with the thicker
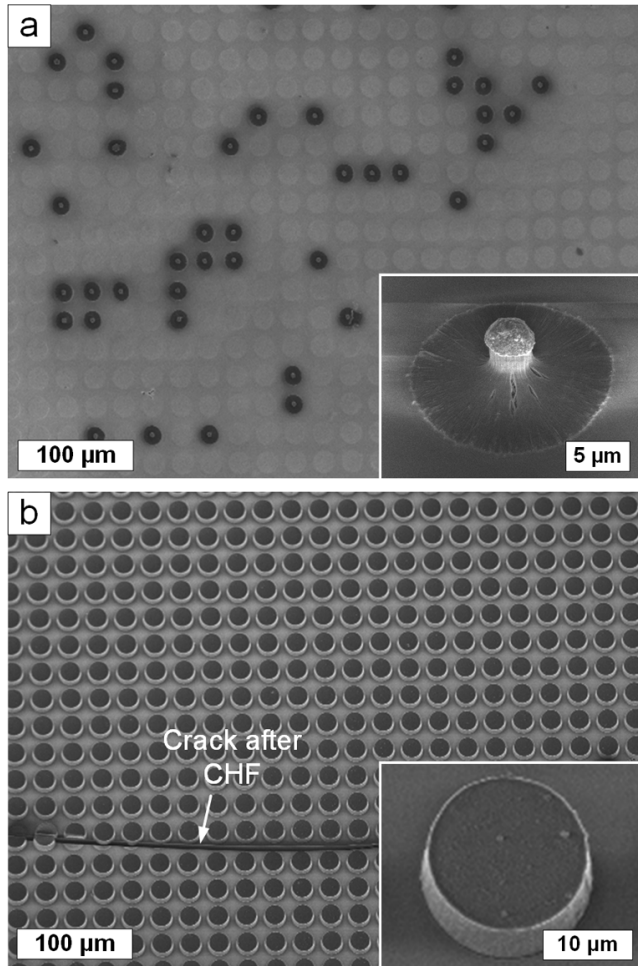

Figure 2. Mechanical stability of $\mathrm{Al}_{2} \mathrm{O}_{3}$-coated $\mathrm{CNT}$ micropillars for pool boiling: (a) CNTs with $20 \mathrm{ALD}$ cycles of $\mathrm{Al}_{2} \mathrm{O}_{3}$ coating detach from the substrate (empty circles) or densify and reach CHF of 150 $\mathrm{W} \mathrm{cm}{ }^{-2}$. (b) CNTs with $150 \mathrm{ALD}$ cycles of $\mathrm{Al}_{2} \mathrm{O}_{3}$ coating remain stable and attached to the substrate after CHF is reached at $235 \mathrm{~W}$ $\mathrm{cm}^{-2}$. Insets show representative micropillars from each case.

$\mathrm{Al}_{2} \mathrm{O}_{3}$ coating reached a $\mathrm{CHF}$ of $235 \mathrm{~W} \mathrm{~cm}^{-2}$, without visible structural deformation or detachment (Figure 2b). This comparison suggests that the mechanical reinforcement provided by the $\mathrm{Al}_{2} \mathrm{O}_{3}$ coating ${ }^{32}$ is critical both to resist capillary densification ${ }^{33}$ and to improve adhesion to the substrate. Therefore, the lower CHF on CNT micropillars with insufficient $\mathrm{Al}_{2} \mathrm{O}_{3}$ coating is likely caused by partial delamination of CNTs during the boiling process.

Thus, further pool boiling experiments used CNT surfaces with ALD coating thickness of $\sim 15 \mathrm{~nm}$ and the dimensions stated above $(20 \mu \mathrm{m}$ pillar diameter, $5 \mu \mathrm{m}$ pillar spacing, and 9 $\mu \mathrm{m}$ pillar height). High-speed optical images (Figure 3a) at $q^{\prime \prime}$ $=20 \mathrm{~W} \mathrm{~cm}^{-2}$ show that individual bubbles nucleate on the $\mathrm{Al}_{2} \mathrm{O}_{3}$-coated $\mathrm{CNT}$ micropillars and grow to their maximum size (typically 5-6 $\mathrm{mm}$ in diameter); then the surrounding liquid rewets the dry spot, with a small macroscopic contact angle on the boiling surface. The bubble then departs, and this periodic process repeats. A synchronized infrared video allows us to correlate the temperature distribution to the bubble dynamics, showing cyclic, temporal cooling of the nucleation site due to bubble formation during a bubble cycle (Figure $3 \mathrm{~b}$ and Video S1). At higher heat fluxes $\left(q^{\prime \prime}>50 \mathrm{~W} \mathrm{~cm}^{-2}\right)$, the bubble density increases dramatically, and the nucleation and departure frequencies also increase (Video S2) before CHF is reached. The CHF values are measured to be 245 and $235 \mathrm{~W}$ $\mathrm{cm}^{-2}$ on two nominally identical samples. Because the CHF is obtained by gradually increasing the applied heat flux in $5 \mathrm{~W}$ $\mathrm{cm}^{-2}$ increments, the uncertainty in CHF measurement is $\sim 5$ $\mathrm{W} \mathrm{cm}^{-2}$. Variation between the two samples may be caused by the surface wettability difference, as the hydrophilicity of $\mathrm{Al}_{2} \mathrm{O}_{3}$ 

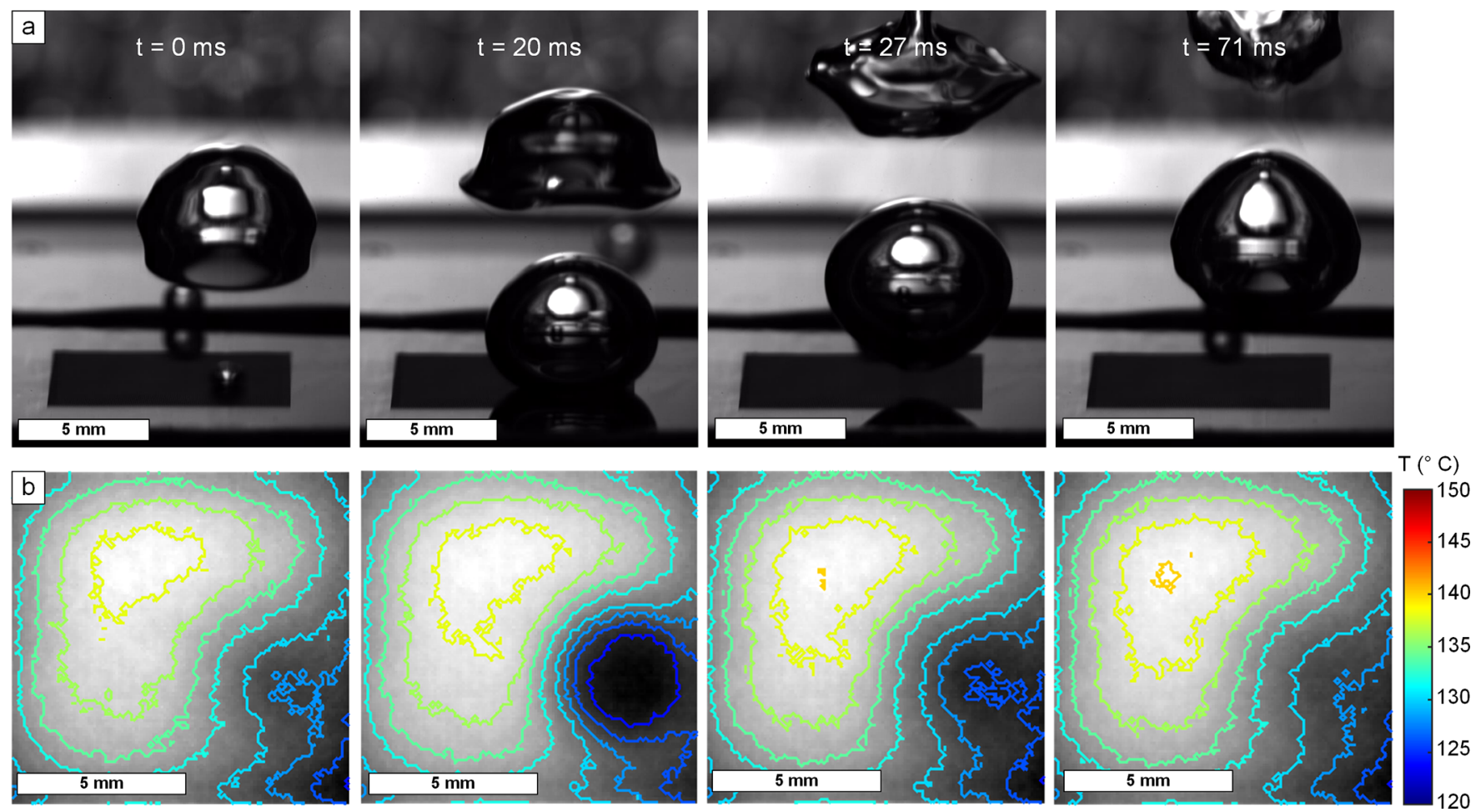

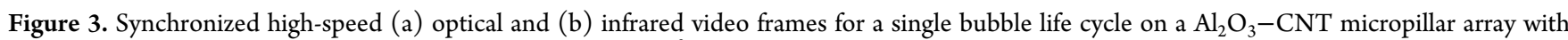
$15 \mathrm{~nm} \mathrm{Al} \mathrm{O}_{3}$ coating thickness at a heat flux $q^{\prime \prime}=20 \mathrm{~W} \mathrm{~cm}^{-2}$.
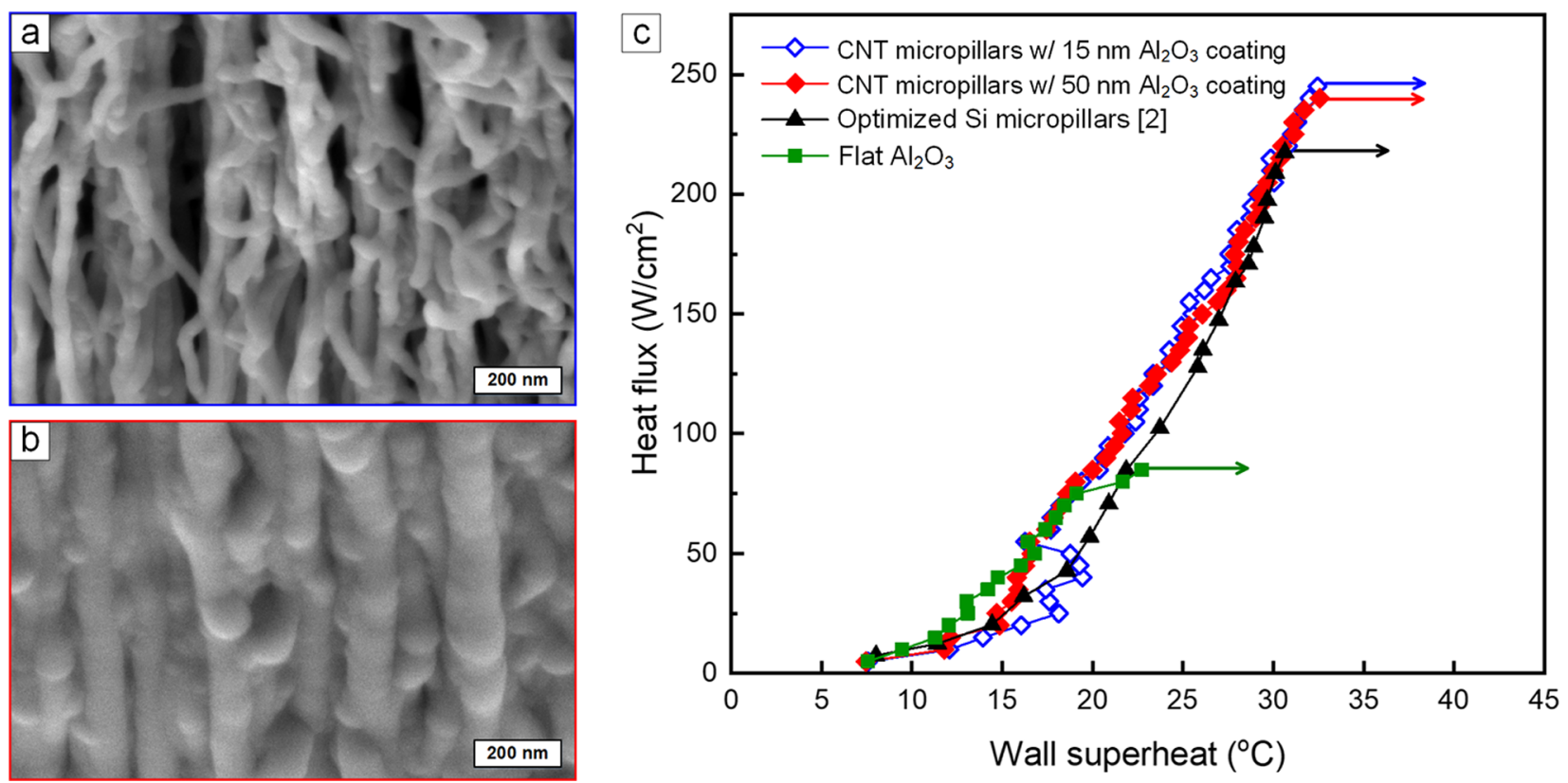

Figure 4. SEM images of sidewalls of $\mathrm{Al}_{2} \mathrm{O}_{3}$-coated CNT micropillars with (a) $15 \mathrm{~nm}$ and (b) $50 \mathrm{~nm}$ thick $\mathrm{Al}_{2} \mathrm{O}_{3}$ coating. (c) Pool boiling curves on CNT micropillars $(20 \mu \mathrm{m}$ pillar diameter, $5 \mu \mathrm{m}$ spacing, and $9 \mu \mathrm{m}$ height $)$ with 15 and $50 \mathrm{~nm}$ thick $\mathrm{Al}_{2} \mathrm{O}_{3}$ coating, Si micropillars with optimized geometry [reproduced with permission from ref 2], and flat $\mathrm{Al}_{2} \mathrm{O}_{3}$ surface. $\mathrm{CHF}$ is signified with an arrow.

degrades with storage time in ambient air, therefore changing its wettability (Figure S5). There is no change within measurement error in the wettability of the $\mathrm{Al}_{2} \mathrm{O}_{3}$ surface before and after the boiling process though (Figure S6) because of the thermal and chemical stability of the $\mathrm{Al}_{2} \mathrm{O}_{3}$ coating. ${ }^{34}$

In Figure 4, boiling curves (i.e., plots of the heat flux versus the substrate superheat) are compared for a flat $\mathrm{Al}_{2} \mathrm{O}_{3}$ surface,
CNT micropillars with $\mathrm{Al}_{2} \mathrm{O}_{3}$ coatings of $\sim 15 \mathrm{~nm}$ (150 ALD cycles) and $\sim 50 \mathrm{~nm}$ (500 ALD cycles), and silicon micropillars with optimized geometry (data from Rahman et al. ${ }^{2}$ ). The measured CHF on the CNT micropillar surface with low porosity is $240 \mathrm{~W} \mathrm{~cm}^{-2}$, and therefore notably the two $\mathrm{Al}_{2} \mathrm{O}_{3}-$ CNT samples have nearly identical boiling behavior in spite of the significantly different porosity $(\sim 70 \%$ and $<10 \%$ for the CNTs with $\sim 15$ and $\sim 50 \mathrm{~nm} \mathrm{Al}_{2} \mathrm{O}_{3}$, respectively). This 
suggests that the nanoporosity of the CNT microstructures plays a negligible role in the CHF. However, the CHF on CNT surfaces is much greater than silicon micropillars and flat $\mathrm{Al}_{2} \mathrm{O}_{3}$; we attribute this to the microscale geometry and roughness of the ceramic-CNT micropillars.

The role of the hierarchical surface geometry on CHF can be understood via the dynamics of liquid imbibition. Liquid imbibition occurs at two length scales (Figure 5a): at the

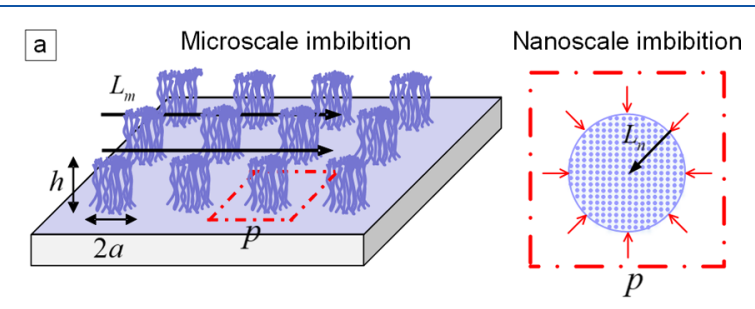

b

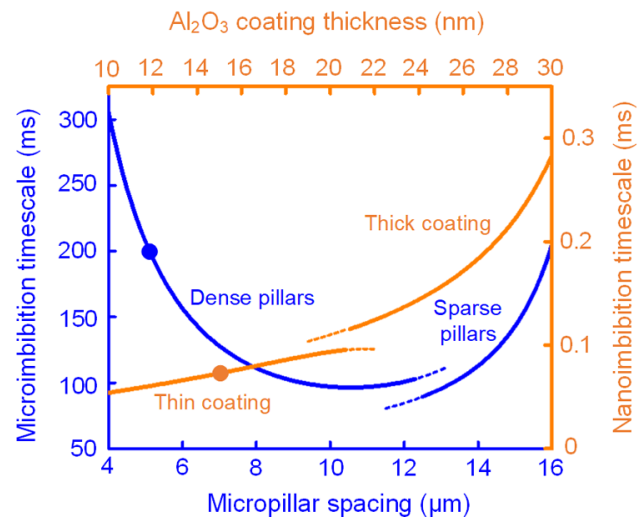

Figure 5. Analysis of microscale and nanoscale liquid imbibition on $\mathrm{Al}_{2} \mathrm{O}_{3}$-coated CNT microstructured surfaces. (a) Schematic of microscale (left) and nanoscale (right) imbibition. (b) Time scales for microscale and nanoscale imbibition as functions of micropillar spacing and $\mathrm{Al}_{2} \mathrm{O}_{3}$ coating thickness, respectively. Dots indicate experiment values for $\mathrm{Al}_{2} \mathrm{O}_{3}$-coated CNT micropillars with $20 \mu \mathrm{m}$ pillar diameter, $5 \mu \mathrm{m}$ pillar spacing, $9 \mu \mathrm{m}$ pillar height, and $15 \mathrm{~nm}$ $\mathrm{Al}_{2} \mathrm{O}_{3}$ coating thickness.

microscale in the spaces between the CNT pillars and at the nanoscale within the porous CNT forest. The micropillar geometry is represented by a square array of circular micropillars with radius $a$, pitch $p$, and height $h$, and the liquid imbibes the surface from the left to the right, with the imbibition distance $L_{\mathrm{m}}$. The water contact angle on the flat $\mathrm{Al}_{2} \mathrm{O}_{3}$ surface is $\theta$. The microscale imbibition speed can be approximated based on the balance of the capillary force and the viscous drag. The capillary driving force $F_{c}$ can be derived by considering the total surface energy change associated with wetting a unit cell of the micropillars (see the Supporting Information):

$$
F_{c}=\frac{\sigma}{p^{2}}\left[2 \pi a h-\left(p^{2}-\pi a^{2}\right)(1-\cos \theta)\right]
$$

The viscous drag at the microscale has two components: viscous drag from the horizontal substrate and from the micropillar sidewalls. Assuming the imbibing liquid front velocity is $V$, the viscous drag from the substrate (per unit width of the liquid film) is estimated as

$$
F_{1} \approx \frac{2 \mu V}{h} L_{\mathrm{m}} \frac{p^{2}-\pi a^{2}}{p^{2}}
$$

assuming a no-slip boundary condition at the substrate and shear-free top liquid surface. The viscous drag from all the micropillars (per unit width of the liquid film) $F_{2}$ is estimated as

$$
F_{2} \approx \frac{2 f h}{3} \frac{L_{\mathrm{m}}}{p^{2}}
$$

where $f$ is the resisting force per unit length on a cylinder for a uniform incoming flow across a square array of cylinders, whose closed-form expression is given by Sangai and Acrivos. ${ }^{35}$ A force balance between the capillary driving force and the viscous drag $F_{c}=F_{1}+F_{2}$ can be established to give the expression of the imbibition time $t_{\mathrm{m}}$ for an imbibition distance $L_{\mathrm{m}}$ :

$$
t_{\mathrm{m}} \approx \frac{\mu}{2 \sigma} \frac{\frac{2\left(p^{2}-\pi a^{2}\right)}{h}+\frac{2 C}{3} h}{2 \pi a h-\left(p^{2}-\pi a^{2}\right)(1-\cos \theta)} L_{\mathrm{m}}^{2}
$$

The constant $C$ in eq 4 is a function of the solid volume fraction of the micropillar array expressed as ${ }^{35}$

$$
\begin{aligned}
& C= \\
& \begin{cases}\frac{4 \pi}{\ln \varepsilon^{-1 / 2}-0.738+\varepsilon-0.887 \varepsilon^{2}+2.038 \varepsilon^{3}} & 0<\varepsilon<0.3 \\
\frac{9 \pi}{2 \sqrt{2}}\left[1-\left(\frac{\varepsilon}{\varepsilon_{\max }}\right)^{1 / 2}\right]^{-5 / 2} & 0.3<\varepsilon<\varepsilon_{\max }=\frac{\pi}{4}\end{cases}
\end{aligned}
$$

where $\varepsilon$ is the solid volume fraction of the pillar arrays $\varepsilon=\frac{\pi a^{2}}{p^{2}}$. The piecewise expressions of this constant $C$ correspond to two analytical approximations applied to sparse $\left(\right.$ small $\left.\frac{a}{p}\right)$ and dense (large $\frac{a}{p}$ ) arrays of micropillars. ${ }^{35}$

Nanoscale imbibition occurs from the edges to the interior of the nanoporous CNT pillars. Applying Darcy's law in the liquid imbibition direction and the boundary conditions gives the nanoscale imbibition time $t_{\mathrm{n}}$ as a function of imbibition distance $L_{\mathrm{n}}$

$$
t_{\mathrm{n}} \approx \frac{\mu \phi r_{\mathrm{m}}}{4 k \sigma \cos \theta} L_{\mathrm{n}}^{2}
$$

where $k$ is the permeability, $\varphi$ is the porosity, and $r_{\mathrm{m}}$ is the pore radius. $^{22}$ The nanoscale permeability can be estimated based on a similar approximation of flow across a square array of nanoscale cylinders, which also have two regimes corresponding to sparse (thin $\mathrm{Al}_{2} \mathrm{O}_{3}$ coating) and dense (thick $\mathrm{Al}_{2} \mathrm{O}_{3}$ coating) arrays of $\mathrm{Al}_{2} \mathrm{O}_{3}-\mathrm{CNTs}$ (see the Supporting Information). Note here the CNT height $h$ does not come into play due to the extremely high aspect ratio of the individual CNTs.

The imbibition distance for a micropillar is roughly its radius. For micropillars with a radius of $10 \mu \mathrm{m}$ and $\sim 15 \mathrm{~nm}$ $\mathrm{Al}_{2} \mathrm{O}_{3}$ coating, the calculated time scale over a length equal to the pillar radius $L_{\mathrm{n}}=10 \mu \mathrm{m}$ is $t_{\mathrm{n}} \sim 0.1 \mathrm{~ms}$ according to eq 6 . In contrast, the microscale imbibition time scale is $t_{\mathrm{m}} \sim 200 \mathrm{~ms}$ (eqs 4 and 5; Figure 5a, left). Here a microscale imbibition distance of $L_{\mathrm{m}}=2 \mathrm{~mm}$ is assumed from the typical bubble radius observed at heat fluxes close to CHF. This indicates that liquid fills the CNT pillars rapidly considering the time scale of microscale imbibition at bubble size $\left(t_{\mathrm{n}} \ll t_{\mathrm{m}}\right.$ because $L_{\mathrm{n}} \ll$ $\left.L_{\mathrm{m}}\right)$. Despite the fact that the speed of nanoscale imbibition is 
much slower than that of microscale imbibition $\left(t_{\mathrm{n}} \gg t_{\mathrm{m}}\right.$ if $L_{\mathrm{n}}=$ $L_{\mathrm{m}}$ ) due to the large viscous drag inside the nanopores, the difference in the imbibition distance becomes the dominating factor. We conclude that the rewetting dynamics after bubble detachment are dominated by the rate of microscale imbibition, and the nanoporosity has little influence on the surface rewetting and resultant CHF. Indeed, the similarity of the CHF values and boiling curves comparing the highly porous versus solid CNT surfaces at heat fluxes greater than 60 $\mathrm{W} \mathrm{cm} \mathrm{cm}^{-2}$ (Figure $4 \mathrm{c}$ ) suggests that the nanoscale imbibition has a negligible effect on the vaporization and liquid rewetting processes at high heat fluxes.

At low heat fluxes $\left(<60 \mathrm{~W} \mathrm{~cm}^{-2}\right)$, we analyzed the frequency and diameter of bubble departure from infrared imaging (Figure S7, see detailed in the Supporting Information). We found that both the bubble departure diameter and bubble cycle time are smaller on the nanoporous surface than those on the solid micropillar surface, and both decrease with increasing heat fluxes on the nanoporous pillar surface (Figure S8). This implies that the porosity of the CNT micropillars, combined with their roughness, influences the bubble dynamics at low heat fluxes. The effect of this nanoimbibition on the bubble dynamics and boiling characteristics may require further studies through high-resolution temperature measurement. ${ }^{36}$

The CHF value of $245 \mathrm{~W} \mathrm{~cm}{ }^{-2}$ achieved on ceramic-CNT microstructured surfaces is among the highest reported for superhydrophilic surfaces in water pool boiling at atmospheric pressure. $^{37}$ The nanotextures of the pillar surface effectively reduce the local water contact angle to zero regardless of the porosity, thereby giving rapid liquid rewetting of the hot spots upon bubble departure. To our knowledge, the highest reported CHF on superhydrophilic surfaces in previous literature is $257 \mathrm{~W} \mathrm{~cm}{ }^{-2}$ for microstructured silicon coated with virus-templated nickel nanostructures. ${ }^{2}$ The effective superhydrophilicity of the $\mathrm{Al}_{2} \mathrm{O}_{3}$-coated CNTs and nanoscale imbibition also give greater heat flux than $\mathrm{Si}$ micropillars with optimized geometry shown $\left(\mathrm{CHF}=217 \mathrm{~W} \mathrm{~cm}^{-2}\right)$ in Figure $4 \mathrm{c}$ (orange curve, reported by Rahman et al. ${ }^{2}$ ), and Si micropillars with optimized geometry and nanoscale surface textures ( $\mathrm{CHF}$ $\left.=211 \mathrm{~W} \mathrm{~cm}^{-2}\right)$.

We hypothesize that even greater CHF could be achieved by improving the hydrophilicity of the coating on the CNTs and by optimizing the microstructure geometry with a slightly larger spacing, as shown in Figure $5 b$ and the imbibition analysis in the Supporting Information. Also, CHF of $420 \mathrm{~W}$ $\mathrm{cm}^{-2}$ has been reported by Kandlikar et al. using a different macroconvection mechanism, where channels with submillimeter width are used to generate separate liquid-vapor pathways for bubble nucleation and departure. ${ }^{38,39}$ This design based on macroconvection could also be easily implemented with micropatterned CNT surfaces, and CNTs may also enable optimization of the passive liquid wicking via nanoporosity. All the $\mathrm{CNT}-\mathrm{Al}_{2} \mathrm{O}_{3}$ structures with the $\mathrm{Al}_{2} \mathrm{O}_{3}$ coating thickness above $15 \mathrm{~nm}$ remain attached to the substrate after our boiling tests, therefore demonstrating structural stability of the texture. Moreover, roll-to-roll patterning and CVD and ALD processes that can be performed over large areas at atmospheric pressure $^{40}$ suggest that CNT-based microstructured boiling surfaces could be manufactured cost-effectively in large-area formats, including on metal substrates and tubes. ${ }^{41,42}$

\section{CONCLUSIONS}

In summary, we find that $\mathrm{Al}_{2} \mathrm{O}_{3}$-coated $\mathrm{CNT}$ microstructures exhibit a high $\mathrm{CHF}\left(245 \mathrm{~W} \mathrm{~cm} \mathrm{~cm}^{-2}\right)$ due to rapid liquid imbibition imparted by their stable microscale geometry and nanoscale texture. Even higher CHF could potentially be achieved by increasing the hydrophilicity of the conformal coating and by optimizing the microstructure pattern. It may also be possible to estimate the $\mathrm{CHF}$ by modeling that considers the microscale structure, nanoscale coating, and local surface wettability. Investigation of the influences of these parameters on the heat transfer coefficient is also of interest for future study. Methods of shaping CNT microstructures into more complex geometries ${ }^{43,44}$ could enable surfaces designed to tailor bubble nucleation and guide bubble departure. Moreover, the electrical conductivity of CNTs could make them useful in manipulating bubble dynamics by using electric forces. $^{45}$ Finally, CNTs can be produced on metal foil substrates in a roll-to-roll fashion, suggesting promise for large-scale manufacturing of such engineered surfaces for boiling heat transfer applications.

\section{ASSOCIATED CONTENT}

\section{S Supporting Information}

The Supporting Information is available free of charge on the ACS Publications website at DOI: 10.1021/acsanm.9b01116.

Figures $\mathrm{S} 1-\mathrm{S} 8$ (PDF)

Video $\mathrm{S} 1$ (AVI)

Video S2 (AVI)

\section{AUTHOR INFORMATION}

\section{Corresponding Author}

*E-mail ajhart@mit.edu.

ORCID $\odot$

Hangbo Zhao: 0000-0001-5229-4192

Kripa K. Varanasi: 0000-0002-6846-152X

A. John Hart: 0000-0002-7372-3512

Notes

The authors declare no competing financial interest.

\section{ACKNOWLEDGMENTS}

Financial support was provided by the MIT Center for Clean Water and Clean Energy supported by the King Fahd University of Petroleum and Minerals, the Air Force Office of Scientific Research (FA9550-16-1-0011), and the MITSkoltech Next Generation Program. Thin film deposition and patterning were performed at the MIT Microsystems Technology Laboratories (MTL). Electron microscopy was performed at the MIT Center for Materials Science and Engineering (CMSE).

\section{REFERENCES}

(1) Dhillon, N. S.; Buongiorno, J.; Varanasi, K. K. Critical Heat Flux Maxima During Boiling Crisis on Textured Surfaces. Nat. Commun. 2015, 6, 8247.

(2) Rahman, M. M.; Ölçeroğlu, E.; McCarthy, M. Role of Wickability on the Critical Heat Flux of Structured Superhydrophilic Surfaces. Langmuir 2014, 30 (37), 11225-11234.

(3) Liter, S. G.; Kaviany, M. Pool-Boiling Chf Enhancement by Modulated Porous-Layer Coating: Theory and Experiment. Int. J. Heat Mass Transfer 2001, 44 (22), 4287-4311. 
(4) Chen, R.; Lu, M.-C.; Srinivasan, V.; Wang, Z.; Cho, H. H.; Majumdar, A. Nanowires for Enhanced Boiling Heat Transfer. Nano Lett. 2009, 9 (2), 548-553.

(5) Shim, D. I.; Choi, G.; Lee, N.; Kim, T.; Kim, B. S.; Cho, H. H. Enhancement of Pool Boiling Heat Transfer Using Aligned Silicon Nanowire Arrays. ACS Appl. Mater. Interfaces 2017, 9 (20), 1759517602.

(6) Chu, K.-H.; Enright, R.; Wang, E. N. Structured Surfaces for Enhanced Pool Boiling Heat Transfer. Appl. Phys. Lett. 2012, 100 (24), 241603.

(7) Kruse, C. M.; Anderson, T.; Wilson, C.; Zuhlke, C.; Alexander, D.; Gogos, G.; Ndao, S. Enhanced Pool-Boiling Heat Transfer and Critical Heat Flux on Femtosecond Laser Processed Stainless Steel Surfaces. Int. J. Heat Mass Transfer 2015, 82, 109-116.

(8) Gregorčič, P.; Zupančič, M.; Golobič, I. Scalable Surface Microstructuring by a Fiber Laser for Controlled Nucleate Boiling Performance of High- and Low-Surface-Tension Fluids. Sci. Rep. 2018, 8 (1), 7461.

(9) Pop, E.; Mann, D.; Wang, Q.; Goodson, K. E.; Dai, H. J. Thermal Conductance of an Individual Single-Wall Carbon Nanotube above Room Temperature. Nano Lett. 2006, 6 (1), 96-100.

(10) Fabris, D.; Rosshirt, M.; Cardenas, C.; Wilhite, P.; Yamada, T.; Yang, C. Y. Application of Carbon Nanotubes to Thermal Interface Materials. J. Electron. Packag. 2011, 133 (2), 020902.

(11) Kaur, S.; Raravikar, N.; Helms, B. A.; Prasher, R.; Ogletree, D. F. Enhanced Thermal Transport at Covalently Functionalized Carbon Nanotube Array Interfaces. Nat. Commun. 2014, 5, 3082.

(12) Boo, C.; Elimelech, M. Thermal Desalination Membranes: Carbon Nanotubes Keep up the Heat. Nat. Nanotechnol. 2017, 12 (6), 501-503.

(13) Huang, Y.-T.; Zhang, H.; Wan, X.-J.; Chen, D.-Z.; Chen, X.-F.; Ye, X.; Ouyang, X.; Qin, S.-Y.; Wen, H.-X.; Tang, J.-N. Carbon Nanotube-Enhanced Double-Walled Phase-Change Microcapsules for Thermal Energy Storage. J. Mater. Chem. A 2017, 5 (16), 7482-7493. (14) Sarafraz, M. M.; Hormozi, F.; Silakhori, M.; Peyghambarzadeh, S. M. On the Fouling Formation of Functionalized and NonFunctionalized Carbon Nanotube Nano-Fluids under Pool Boiling Condition. Appl. Therm. Eng. 2016, 95, 433-444.

(15) Sarafraz, M. M.; Hormozi, F.; Peyghambarzadeh, S. M. Pool Boiling Heat Transfer to Aqueous Alumina Nano-Fluids on the Plain and Concentric Circular Micro-Structured (CCM) Surfaces. Exp. Therm. Fluid Sci. 2016, 72, 125-139.

(16) Cai, Q.; Chen, C.-L. Design and Test of Carbon Nanotube Biwick Structure for High-Heat-Flux Phase Change Heat Transfer. J. Heat Transfer 2010, 132 (5), 052403.

(17) Cui, Y.; Liu, C.; Hu, S.; Yu, X. The Experimental Exploration of Carbon Nanofiber and Carbon Nanotube Additives on Thermal Behavior of Phase Change Materials. Sol. Energy Mater. Sol. Cells 2011, 95 (4), 1208-1212.

(18) Dharmendra, M.; Suresh, S.; Kumar, C. S. S.; Yang, Q. Pool Boiling Heat Transfer Enhancement Using Vertically Aligned Carbon Nanotube Coatings on a Copper Substrate. Appl. Therm. Eng. 2016, 99, 61-71.

(19) Lee, S.; Seo, G. H.; Lee, S.; Jeong, U.; Lee, S. J.; Kim, S. J.; Choi, W. Layer-by-Layer Carbon Nanotube Coatings for Enhanced Pool Boiling Heat Transfer on Metal Surfaces. Carbon 2016, 107, 607-618.

(20) Ahn, H. S.; Sinha, N.; Zhang, M.; Banerjee, D.; Fang, S.; Baughman, R. H. Pool Boiling Experiments on Multiwalled Carbon Nanotube (MWCNT) Forests. J. Heat Transfer 2006, 128 (12), 1335-1342.

(21) Ujereh, S.; Fisher, T.; Mudawar, I. Effects of Carbon Nanotube Arrays on Nucleate Pool Boiling. Int. J. Heat Mass Transfer 2007, 50 (19), 4023-4038.

(22) Zhao, H.; Jacob, C.; Stone, H. A.; Hart, A. J. Liquid Imbibition in Ceramic-Coated Carbon Nanotube Films. Langmuir 2016, 32 (48), $12686-12692$.
(23) Bertossi, R.; Caney, N.; Gruss, J. A.; Dijon, J.; Fournier, A.; Marty, P. Influence of Carbon Nanotubes on Deionized Water Pool Boiling Performances. Exp. Therm. Fluid Sci. 2015, 61, 187-193.

(24) Oliver, C. R.; Polsen, E. S.; Meshot, E. R.; Tawfick, S.; Park, S. J.; Bedewy, M.; Hart, A. J. Statistical Analysis of Variation in Laboratory Growth of Carbon Nanotube Forests and Recommendations for Improved Consistency. ACS Nano 2013, 7 (4), 3565-3580.

(25) Dash, S.; Rapoport, L.; Varanasi, K. K. Crystallization-Induced Fouling During Boiling: Formation Mechanisms to Mitigation Approaches. Langmuir 2018, 34 (3), 782-788.

(26) Lushington, A.; Liu, J.; Tang, Y.; Li, R.; Sun, X. Surface Modification of Nitrogen-Doped Carbon Nanotubes by Ozone via Atomic Layer Deposition. J. Vac. Sci. Technol., A 2014, 32 (1), 01A124.

(27) Azimi, G.; Dhiman, R.; Kwon, H.-M.; Paxson, A. T.; Varanasi, K. K. Hydrophobicity of Rare-Earth Oxide Ceramics. Nat. Mater. 2013, 12 (4), 315-320.

(28) Karaman, M. E.; Antelmi, D. A.; Pashley, R. M. The Production of Stable Hydrophobic Surfaces by the Adsorption of Hydrocarbon and Fluorocarbon Carboxylic Acids onto Alumina Substrates. Colloids Surf., A 2001, 182 (1-3), 285-298.

(29) Xiao, R.; Enright, R.; Wang, E. N. Prediction and Optimization of Liquid Propagation in Micropillar Arrays. Langmuir 2010, 26 (19), 15070-15075.

(30) Ishino, C.; Reyssat, M.; Reyssat, E.; Okumura, K.; Quéré, D. Wicking within Forests of Micropillars. EPL 2007, 79 (5), 56005.

(31) Bedewy, M.; Meshot, E. R.; Reinker, M. J.; Hart, A. J. Population Growth Dynamics of Carbon Nanotubes. ACS Nano 2011, 5 (11), 8974-8989.

(32) Brieland-Shoultz, A.; Tawfick, S.; Park, S. J.; Bedewy, M.; Maschmann, M. R.; Baur, J. W.; Hart, A. J. Scaling the Stiffness, Strength, and Toughness of Ceramic-Coated Nanotube Foams into the Structural Regime. Adv. Funct. Mater. 2014, 24 (36), 5728-5735.

(33) Tawfick, S.; Zhao, Z.; Maschmann, M.; Brieland-Shoultz, A.; De Volder, M.; Baur, J. W.; Lu, W.; Hart, A. J. Mechanics of Capillary Forming of Aligned Carbon Nanotube Assemblies. Langmuir 2013, 29 (17), 5190-5198.

(34) Correa, G. C.; Bao, B.; Strandwitz, N. C. Chemical Stability of Titania and Alumina Thin Films Formed by Atomic Layer Deposition. ACS Appl. Mater. Interfaces 2015, 7 (27), 14816-14821.

(35) Sangani, A. S.; Acrivos, A. Slow Flow Past Periodic Arrays of Cylinders with Application to Heat Transfer. Int. J. Multiphase Flow 1982, 8 (3), 193-206.

(36) Bucci, M.; Richenderfer, A.; Su, G.-Y.; McKrell, T.; Buongiorno, J. A Mechanistic IR Calibration Technique for Boiling Heat Transfer Investigations. Int. J. Multiphase Flow 2016, 83, 115127.

(37) Cho, H. J.; Preston, D. J.; Zhu, Y. Y.; Wang, E. N. Nanoengineered Materials for Liquid-Vapour Phase-Change Heat Transfer. Nat. Rev. Mater. 2016, 2 (2), 16092.

(38) Kandlikar, S. G. Controlling Bubble Motion over Heated Surface through Evaporation Momentum Force to Enhance Pool Boiling Heat Transfer. Appl. Phys. Lett. 2013, 102 (5), 051611.

(39) Jaikumar, A.; Kandlikar, S. G. Ultra-High Pool Boiling Performance and Effect of Channel Width with Selectively Coated Open Microchannels. Int. J. Heat Mass Transfer 2016, 95, 795-805.

(40) Mousa, M. B. M.; Oldham, C. J.; Parsons, G. N. Atmospheric Pressure Atomic Layer Deposition of $\mathrm{Al}_{2} \mathrm{O}_{3}$ Using Trimethyl Aluminum and Ozone. Langmuir 2014, 30 (13), 3741-3748.

(41) Hiraoka, T.; Yamada, T.; Hata, K.; Futaba, D. N.; Kurachi, H.; Uemura, S.; Yumura, M.; Iijima, S. Synthesis of Single- and DoubleWalled Carbon Nanotube Forests on Conducting Metal Foils. J. Am. Chem. Soc. 2006, 128 (41), 13338-13339.

(42) Pattinson, S. W.; Viswanath, B.; Zakharov, D. N.; Li, J.; Stach, E. A.; Hart, A. J. Mechanism and Enhanced Yield of Carbon Nanotube Growth on Stainless Steel by Oxygen-Induced Surface Reconstruction. Chem. Mater. 2015, 27 (3), 932-937.

(43) Park, S. J.; Zhao, H.; Kim, S.; De Volder, M.; Hart, A. J. Predictive Synthesis of Freeform Carbon Nanotube Microarchitec- 
tures by Strain-Engineered Chemical Vapor Deposition. Small 2016, 12 (32), 4393-4403.

(44) Zhao, H.; Park, S. J.; Solomon, B. R.; Kim, S.; Soto, D.; Paxson, A. T.; Varanasi, K. K.; Hart, A. J. Synthetic Butterfly Scale Surfaces with Compliance-Tailored Anisotropic Drop Adhesion. Adv. Mater. 2019, 31 (14), 1807686.

(45) Di Marco, P; Morganti, N; Saccone, G. Electric Field Effects on the Dynamics of Bubble Detachment from an Inclined Surface. J. Phys.: Conf. Ser. 2015, 655 (1), 012044. 